\title{
COMMENTARY: ACTIONS IN THE PIPELINE AND THE WAY FORWARD TO REDUCE MATERNAL AND PERINATAL MORTALITY IN ETHIOPIA
}

\section{Yifru Berhan", Asres Berhan²}

\section{INTRODUCTION}

Historically, in the late 1970's, Ethiopia adopted a six-tier health plan as the national strategy to achieve equitable access to health services for all. The 1993-health policy, however, adopted a fourtier system consisting of a primary health care unit (five satellite health posts and one health center), a district hospital, a regional/zonal hospital and a specialized hospital), which primarily gave emphasis to prevention and primary health care (1, 2).

Very recently, the health sector has introduced a three-tier system that includes a primary health care unit (PHCU), general hospitals and specialized hospitals. The PHCU consists of five satellite health posts, one health center and one primary hospital (see below for the detail). The Federal Ministry of Health (FMOH) of Ethiopia formulated and launched the 20-year rolling Health Sector Development program (HSDP) in 1998, which has reached its fourth stage (HSDP IV). Among the foremost priorities given by the HSDP IV are maternal health and neonatal health (3).

The HDSP IV has identified the following performance indicators that reflect improved access in maternal and neonatal health: decrease the maternal mortality ratio to $267 / 100,000$ live births, increase the contraceptive prevalence rate to $66 \%$, reduce teenage pregnancy to $5 \%$, increase focused $\mathrm{ANC} 1+$ to $90 \%$ and $\mathrm{ANC} 4+$ to $86 \%$, increase deliveries attended by skilled birth attendants to $62 \%$ and decrease infant mortality rate of 31/1000 live births (3). The Health Extension Program (HEP) (established in 2003 and became operational in 2005) was primarily designed to reduce maternal and neonatal mortality through the provision of family planning at the lowest level (household, health post) and provision of clean and safe delivery services at home and in the health posts (1). The health extension workers are not only expected to provide service to the community in their vicinity but also to bridge the gap between the community and health facilities.

Taking these into account, the goals of the Ethiopian National Reproductive Health Strategy in the years 2006-2015 are: reducing of unwanted pregnancies to enable individuals to achieve their desired family size, reduction of maternal and neonatal mortality, reduction of HIV infection and improvement of the quality of life of people living with the virus, and enhancement of the reproductive health and well-being of the youth (4).

To materialize the planned goals, the strategy has identified six priority areas (social and cultural determinants of women's reproductive health, fertility and family planning, maternal and newborn health, HIV/AIDS, reproductive health of young people, reproductive organ cancers) and three levels of intervention (community, system and policy) (4).

To address the maternal and newborn health issues, there are some working guidelines developed by FMOH. Among others, the National Guideline for Prevention of Mother to Child

DOI: http://dx.doi.org/10.4314/ejhs.v24i1.13S

\footnotetext{
${ }^{1}$ Hawassa University, College of Medicine and Health Sciences, Department of Gynecology-Obstetrics

${ }^{2}$ Hawassa University, College of Medicine and Health Sciences, Department of Pharmacology

Corresponding Author: Yifru Berhan, Email: yifrub@yahoo.com
} 
Transmission of HIV, Adolescent and Youth Reproductive Health Strategy, the Revised Abortion Law and the Management Protocol on Selected Obstetric Topics are at the forefront.

Very recently, the FMOH has been implementing a Health Management Information System (HMIS) across the country for regular monitoring and evaluation of programs and to improve service delivery and health care management, which is expected to provide comprehensive information on maternal and neonatal health service and outcome at the health facility level. The ministry also uses regular surveys like Ethiopian Demographic and Health Survey (DHS) to generate data on the set indicators.

Another recent development is the establishment of a Women Health Development Team (previously, The Health Development Army) at the community level each composed of 30 households. There are 5 'nucleus' units under it and each has a leader.

The purposes of this commentary are: to highlight the already implemented actions on health and predict what to come, to show supportive evidences from the experience of other countries, and to propose new strategies to reduce the maternal and perinatal mortality in Ethiopia.

\section{A) Actions in the pipeline to reduce the maternal and perinatal mortality in Ethiopia}

Now-a-days, the Ethiopian government's commitment is above all times to improve the maternal and perinatal health in particular. As a result, a breakthrough in maternal and perinatal mortality reduction is highly anticipated in the coming ten to fifteen years. Some of the inputs and processes which make the likelihood of maternal and perinatal mortality reduction foreseeable are the ongoing construction of a large number of hospitals and health centers, the human resource development for health, roads construction, ambulance procurement, universal education and the continuously growing economy.

\section{Construction of hospitals and health centers}

The targets of HSDP IV are one health post for 3,000- 5,000 population, one health center for 40,000 (urban) and 15,000-25,000 (rural) population, one primary hospital for 60,000 100,000 population, one general hospital for $1-1.5$ million population, and one specialized hospital for 3.5-5 million population (3). To achieve these targets, the government of Ethiopia has already started constructing 800 primary hospitals across the nation (more than 12-fold of the hospitals in 2006). The authors have got the chance to observe 18 primary hospitals under construction (almost being finalized) in three zones in the Southern Regional State. They also have the information that similar undertakings (more than 110) are under construction in other regional states. The majority of these constructions base in already functioning health centers that will enable them to provide major emergency surgical procedures which is one of the signal function of Comprehensive Emergency Obstetric Care.

So far, nearly 16,000 health posts and more than 3500 health centers have been constructed, which is about 6 times higher than the number of health centers in 2005 (5). The plan is to construct 200 general hospitals and 50 specialized hospitals (more than 20-fold of the existing specialized hospitals) in the coming few years (Federal Ministry of Health unpublished report). Taking the recent experiences on the government's commitment for infrastructure construction, the authors are confident that all or beyond the planned construction will be materialized very soon. This is a breakthrough action in terms of increasing the hospitals to population ratio. Figure 1 shows the predicted hospitals to population ratio (number of hospitals per 100,000 people by type of hospitals). The scheme of one primary hospital for 100,000 people is expected to be achieved by 2025.

The government's commitment is not only limited to constructing health facilities but also furnishing and equipping the existing ones with essential medical equipment. Among others, FMOH is going to equip 8 public hospitals with high tech radiology equipment including MRI and CT scan. For this purpose, all the selected hospitals are finalizing their space preparation for equipment installment. The Minister with the Ministry of Health has also promised to establish 5 renal dialysis centers, which will be helping several mothers dying of acute renal failure commonly due to eclampsia and placental abruption. 


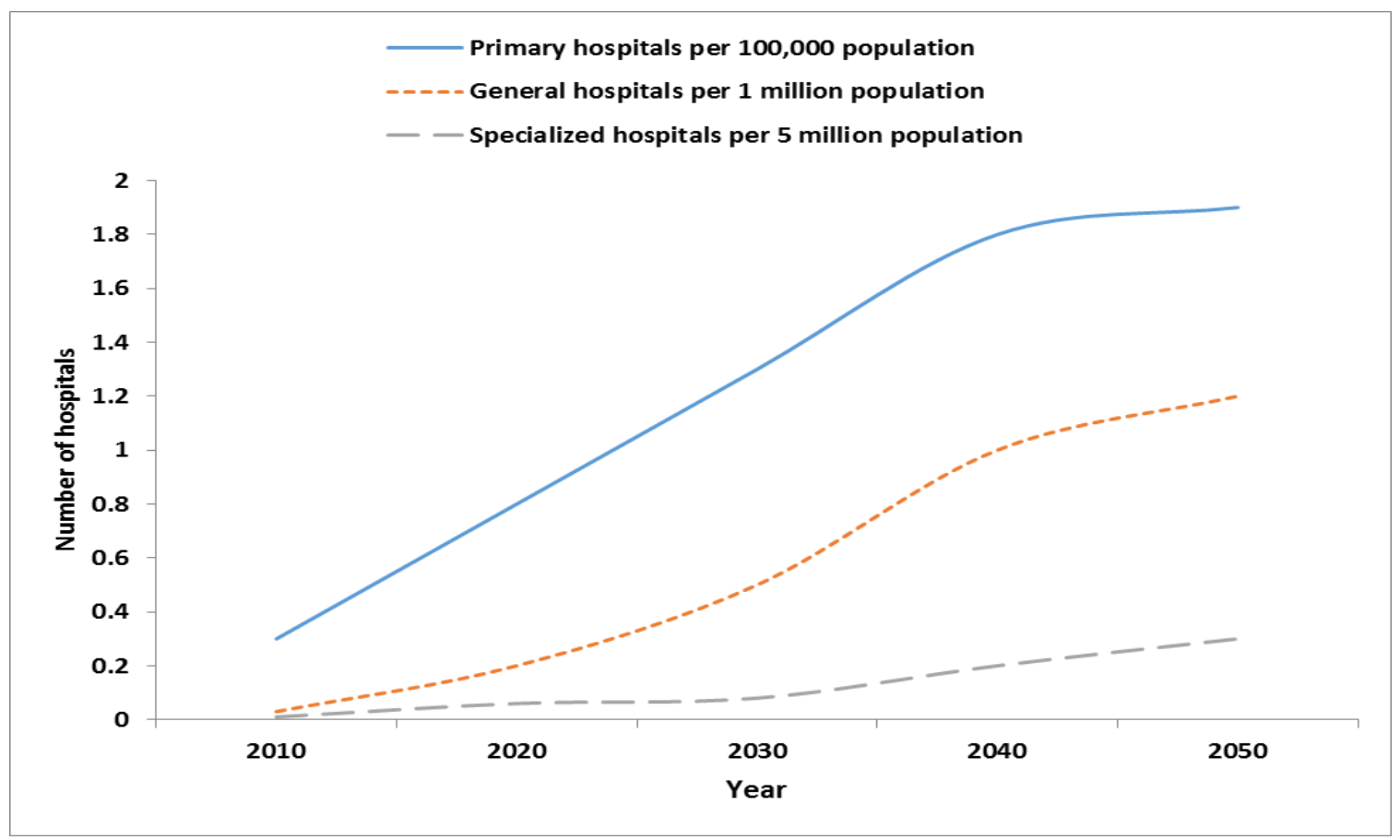

Figure 1: Predicted number of hospitals by type, Ethiopia, 2010-2050

\section{Human resource development for health}

Specifically, the FMOH's commitment along with partners' collaboration in supporting the health professional training is another strong evidence to aspire a significant reduction in maternal and perinatal mortality in the coming 10 years. Some of the breakthroughs: the number of medical schools was 3 for more than 40 years and 5 for the last 10 years. This time, 19 university based medical schools (16 government and 3 private owned) and 13 public hospital based medical schools (total 32) have been established with an overall enrolment capacity of more than 3000 medical students per annum.

The government is still aspiring to increase the annual medical doctors' production to above 4,000 or more in the years to come. However, if the current admission rate continues, definitely, more than 3,000 medical doctors will graduate every year in the coming 7 years and later. With this pace of admission and taking the projected population size and at least $10 \%$ physician attrition from the public health facilities, the number of general practitioners per 100,000 population by 2020 is predicted to be more than 15-fold of the 2010 (Figure 2). The number of clinical specialists in the coming 40 years in reference to the projected population size, however, will depend on the implementation of the new postgraduate admission strategy or continuation of the existing admission program as described below in detail.

Specific to continually increasing the admission of medical students, the authors have serious concerns. Increasing the admission of medical students beyond 4,000 per year may go much higher than the demand. In other words, it is very unlikely that the health system of Ethiopia accommodates the graduates to come. It is good to see this issue from different angles.

The stretched assumptions are:

1) All 1050 hospitals planned to be constructed and the 124 existing public hospitals (total 1174 hospitals) become operational by 2025 ;

2) The Ethiopian population size is projected to be about 113 million by 2025 and 186 million by 2050 (United Nation Population Fund - UNFPA);

3) There will be about $10 \%$ attrition of the general practitioners from public health sector; and 
4) A significant number of general practitioners are expected to join postgraduate program provided that the scale up specialty training strategy is implemented.

\section{Scenario I (Continuing with the existing admission, 4000/year)}

- As of 2015 and onwards, about 3500 general practitioners will graduate every year.

- There will be more than 35,000 graduates plus those physicians already in the system (estimated to be around 3800) by 2025.

- With about $10 \%$ attrition, there will be about 31 medical doctors for every 100,000 population. Similarly, each hospital will have a share of 30 medical doctors by 2025 .

\section{Scenario II (Doubling the existing admission to 8,000/year)}

- As of 2015 and onwards, about 7000 general practitioners will graduate every year.

- As a result, there will be more than 70,000 graduates plus those physicians already in the system (estimated to be around 3800) by 2025 .

- With about $10 \%$ attrition, the number of medical doctors for every 100,000 people will be about 59. Similarly, there will be 57 medical doctors per hospital by 2025 .

What repeatedly pointed out by different higher officials is to increase the medical students' admission to 9,000 per year. The comment we have is that the government should see this issue very seriously for:

- In the best scenario (all hospitals become operational), since more than $75 \%$ of the hospitals planned to be constructed are primary hospitals, it is unlikely that the graduates get job in the hospital setting;

- The construction of the planned hospitals is not parellelly going well with the production of medical doctors, and is unlikely to be completed before 2025 ;
- As the number of admission increases, the quality of training will be compromised;

- The existing medical schools (the conventional or the innovative) are not prepared to admit any more; and

- The innovative medical schools are draining the relatively competent health officers, which is becoming a threat for the surgical health officer program.

Therefore, the current admission rate needs to be maintained for some time and a lot has to be done to maximize the graduates' performance.

In general, the mid-level health professional training in the public and private health institution is very huge. The production is probably beyond the demand, with all the limitations pertaining to quality of training and certification. Specific to maternal and perinatal health, health professionals primarily involved in the clinical service are gynecologists, surgical officers and midwives.

The surgical officer training is a new initiative; a three year postgraduate training program at master's level was started initially in 2009 in three universities (Hawassa leading by developing the curriculum and implementation schemes). This program is primarily intended to address maternal and perinatal health issues in the remote areas. The program is currently going well in 12 universities by enrolling more than 750 students. So far, more than 100 graduated, and the majority of them are working in the district hospitals.

Among other medical and surgical therapies for emergency obstetric and gynecologic problems, the graduates are expected to perform an emergency cesarean section, cesarean hysterectomy, hysterectomy for uterine rupture, laparotomy for gynecologic and surgical acute abdomen. As a result, the rampant obstructed labor and its complications (uterine rupture, fistula, high perinatal and maternal mortality) among the rural women may become a history in the coming ten to fifteen years.

The number of midwives is still very low for the general population. But, with the continuously increasing annual enrollment capacity, the required number seems also achievable. The big challenge is with the specialty training program (see below in the planned actions). 


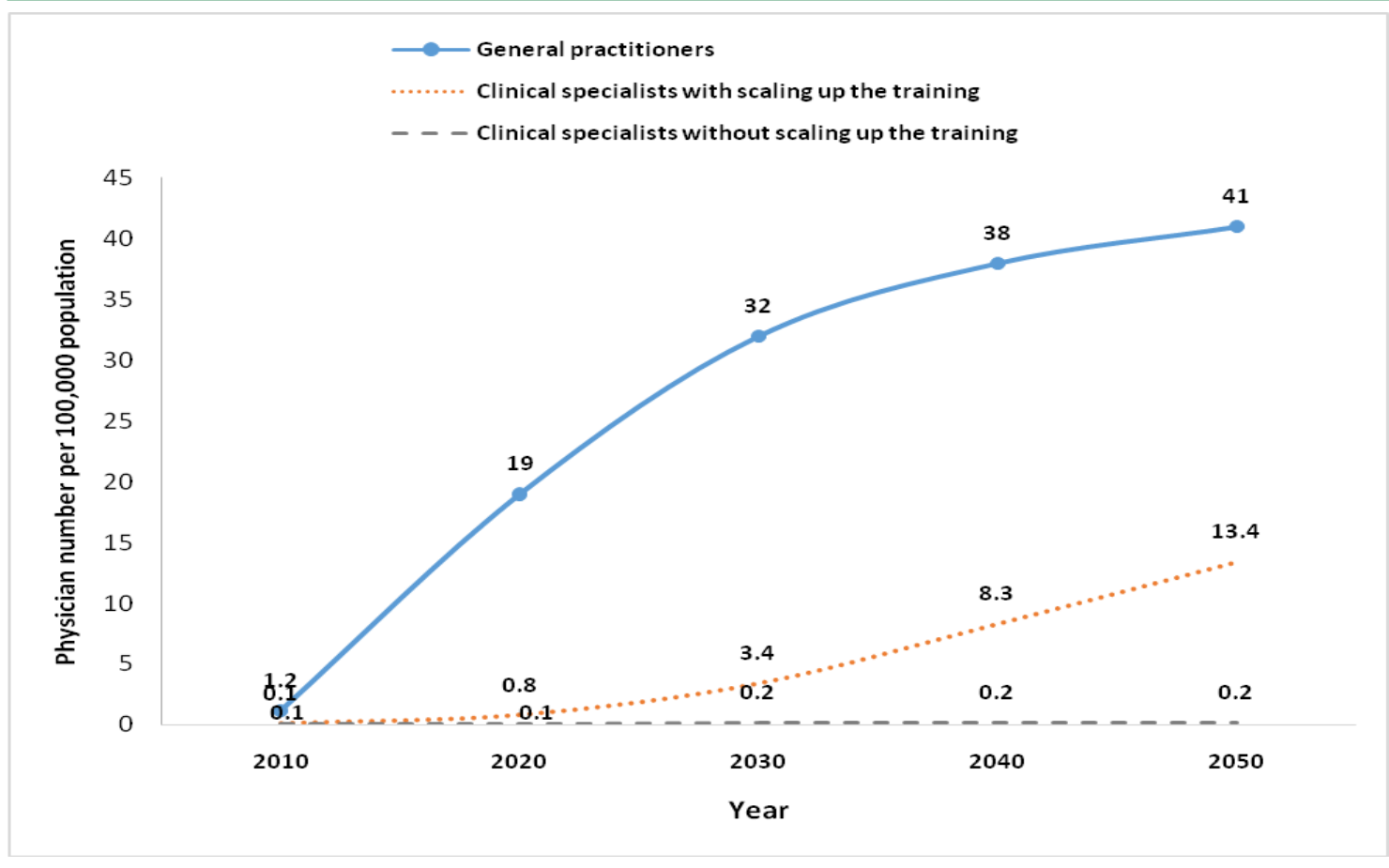

Figure 2: Predicted number of physicians in the public sector per 100,000 people

\section{Universal primary education}

As discussed before (6), education is a powerful tool to bring a behavioral change in reproductive health at the individual and community level. Educated couples decide for themselves to get married usually when their ages reach in the 20s; decide to have a limited number of babies with adequate spacing; start antenatal care as early as possible; commonly give birth in health facilities; and bring sick mothers and babies to health facilities as soon as possible $(7,8)$. This is also already a well observed fact among the civilized society. Some years back, the total fertility rate in Addis Ababa was reported as less than replacement $(<2.0$ children per woman), which can be taken as a proxy indicator for the influence of information and access on fertility rate.

What makes the future bright in Ethiopia is that the gross enrollment capacity in primary school has risen from 32\% in 1990/91 to over 91\% in $2006 / 07$. Probably these days, children primary school enrollment is close to $98 \%$ except the pastoral area although there are drop out problems mainly in the rural area. The interesting change is that the male to female proportion in class is becoming nearly $1: 1$. The authors deduced that educating the future mothers is a big investment for the country to see the radical change in maternal and perinatal health. In short, the huge investment in education by the Ethiopian government is another breakthrough action to make a difference in maternal and perinatal health in the years to come.

\section{Transport access and ambulances procurement}

It is obvious that transport is important for pregnant women in accessing health facilities. Whenever a constructed road is inaugurated, the first reaction of the rural people is, "Before this road was constructed, many laboring mothers died at home; even when we attempt to take them to a health facility, they usually die on a locally made stretcher-Kareza". A systematic review has also shown a significant reduction in perinatal and neonatal mortality when their parents live closer to health facilities (9).

These days, it is clear how much the government is investing in road construction in both rural and urban areas. Furthermore, the procurement of 840 ambulances by the government at one time for public use is a new 
chapter in Ethiopian history. All these ambulances were already distributed to each woreda and are currently on service. Recently, the authors had a chance to visit some of the remote areas in Ethiopia, where home delivery used to be $100 \%$. After the ambulances were donated to those remote areas, the community informed him that no maternal death occurred in 6 months period at home. If a laboring woman fails to deliver within 12 hours, they will call the ambulance driver to take her to a district hospital (maximum distance about $50 \mathrm{~km}$ ). Therefore, the ongoing road construction and ambulance procurement are some of the huge investments that are likely to increase the maternal and perinatal survival in the near future.

\section{The country's economy}

Currently, it is very common to hear and read the following statement. "Ethiopia is one of the fastest-growing economies in the world". The "economist" also puts Ethiopia as the third fastestgrowing economy (the annual average GDP growth for Ethiopia for 2001-2010 and 2011-2015 was estimated to be $8.4 \%$ and $7.2 \%$ (The Economist; IMF). Thus, probably secondary to the universal primary education, the growing economy will bring a remarkable change in the maternal and perinatal health in Ethiopia.

Taking into account the already implemented multisectoral growth and development undertakings and others to come, the authors predicted the maternal mortality ratio for Ethiopia for the coming 40 years (Figure 3). Since the baselines for the millennium development goals (MDGs) was the health status in 1990, the maternal mortality ratio (MMR) estimated by WHO for the 1990 for Ethiopia (950 per 100,000 live births) was taken as a baseline. It was intended to reduce the maternal mortality by twothirds $(75 \%)$ by the year 2015. However, according to 2011 Ethiopian demographic and health survey (EDHS), the gross reduction in MMR was only about 29\% (10). The authors of this commentary calculated that the $75 \%$ reduction of MMR from the baseline is likely to be achieved by the year 2025 (250 per 100,000 live births or the HSDP IV target 267 per 100,000 live births).

In summary, increasing the health facilities by several folds, increasing the number of health professionals (general practitioners, surgical officers and midwives), increasing the transport access and ambulance procurement, availing universal primary education and the fast economic growth are very promising actions to reduce the maternal and perinatal mortality in Ethiopia.

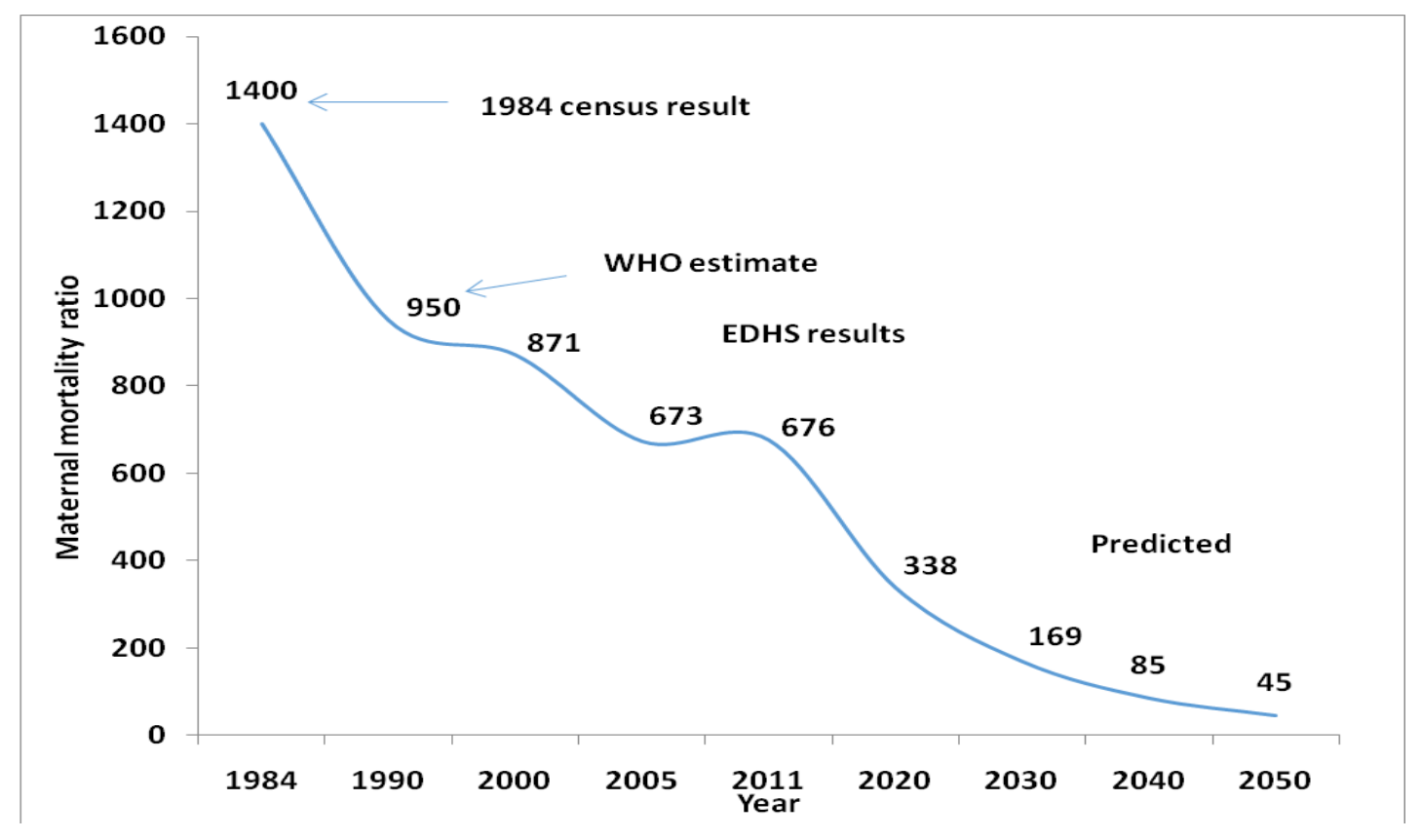

Figure 3:. Predicted maternal mortality ratio for Ethiopia for 2020 to 2050 


\section{B) The way forward to reduce maternal and perinatal mortality in Ethiopia}

This review has identified several health facility, community and resource and education based problems, which likely have direct or indirect contribution to the high maternal and perinatal mortality. Among several identified gaps, some will be achievable in the near future with the already implemented growth and development plan.

The authors, however, have recommended more to be done in the clinical postgraduate program, basic and comprehensive emergency obstetric care (BEmOC and CEmOC) in service training, availing injectable and implant contraceptives to the rural women, establishing blood banks at the zonal level, including iron infusion in the essential drugs and supplies list, availing magnesium sulphate and misoprostol to all health centers and hospitals, establishing neonatal intensive care units in all hospitals, establishing maternity waiting areas, scaling up the women's group approach, establishing women-health professionals networking and instituting the planned health insurance system.

\section{Scaling up the specialty training program: Which strategy can work better?}

Overall, the number of all type of specialists in the public health sector was extremely low in 2011 (605 for 82 million people) (11). This time, the clinical specialist to population ratio in the public hospitals may even be the lowest ever. Unless an immediate action is taken to significantly increase the specialists' number, the challenge may go beyond providing better clinical service. To begin with, the specialists are the trainers for the undergraduate medical students, health officers, and postgraduate students (residents and surgical officers). Furthermore, the specialists have a critical role in clinical service leadership, conducting research and leading the planned women-health professionals' network.

Currently, because of their limited number in every medical school, both the undergraduate and postgraduate programs are likely to be severely compromised. Secondly, the postgraduate enrollment capacity of the old medical schools is very limited. With the existing medical school system, it is hard to make a difference in their enrollment capacity in the years to come. Similarly, with the existing number of specialists, university affiliated hospitals are also unlikely to be a postgraduate training site. It is hard to find one surgeon and one gynecologist in the majority of general hospitals. Thirdly, to the authors' knowledge, scaling up the specialty program is not yet in the forefront agenda of the government (see below for the actions to be undertaken).

Postgraduate program in clinical specialty including obstetrics and gynecology (Ob/Gyn) was launched about 34 years ago in Addis Ababa University (1979) (5). About 6-8 years back, few specialty programs were opened in Jimma and Gondar Universities. Before about a year, Mekele University announced the launching of specialty programs in few clinical disciplines. Hawassa University is also going to admit postgraduate students in late 2013 in four clinical fields (Ob/Gyn, Surgery, Internal Medicine and Pediatrics). Despite the long history of the specialty program, there has been a chronic shortage of specialists in all types of clinical fields. Beyond the postgraduate schools' low capacity, the chronic shortage of specialists was somehow the reflection of the chronic shortage of general practitioners (5).

Although the issue of clinical competency of the graduates is still questionable because of their large number in each class and lack of senior instructors in several non-university based medical schools, the shortage of general practitioners is no longer going to be an agenda for this country. Similarly, the extremely low number of specialists across all clinical fields should not continue as an impediment to the change in maternal and other health issues aspired to. The big question is, "How can the specialty training be scaled up?"

As described above, with the existing postgraduate admission modality, this country may continue to have a critical shortage of specialists in all clinical fields for the coming 2030 years. The existing postgraduate program in clinical specialty is to let students have a university based and few university affiliated hospitals based theoretical and practical training. As a result, the enrollment capacity of each clinical department is limited to 10-20 students per year. In the worst scenariom because of the low number of applicants and in some departments due to the limited number of staff, it is not unusual to 
admit 0-3 students per year even in the old medical schools.

According to the author's opinion, in the coming years, there are three big challenges we are going to face:

- The annual medical student enrollment capacity of the 32 medical schools will continue growing. If we do not get prepared ahead of the days to come, who is going to teach the huge number of students in each medical school?

- For the 800 district hospitals, about 2000 surgical officers are going to graduate to perform emergency surgical procedures (Obstetrics and gynecology, general surgery). The number of general and specialized hospitals is also going to increase by several folds from their current number. In parallel, the number of private hospitals and clinics is increasing with alarming rate. Apart from out of the country migration, the private health facilities will continue to be the greener pastures for the few specialists in the country. Therefore, who is going to work in the general and specialized hospitals unless something is done to scale up the admission for specialty training?

- As the number of general practitioners dramatically increases in the coming years, the number of applicants for specialty training may even increase exponentially (because of the cumulative effect or several years backlog). Who is going to train them and where are they going to be trained?

These challenges imply that scaling up the specialty program is a top priority. Furthermore, admitting the coming general practitioners to the postgraduate program as soon as possible will have multiple advantages:

- To improve their questionable clinical knowledge and skill they acquired during undergraduate training;

- To get adequate number of instructors for the undergraduate students in a short period of time (the postgraduate students will be instructors for the undergraduate students);
- To get adequate number of instructors for the undergraduate and postgraduate programs in the long run.

- To retain the medical doctors in the country and in the public sector in particular;

- To improve the general practitioners' academic career;

- To improve the quality of clinical service where they will be assigned as a resident for clinical practice; and

- To improve the clinical service.

In short, admitting an adequate number of the new graduates to the postgraduate program as early as possible should be taken as a top priority for 1) the betterment of the ongoing medical education and 2) remarkable improvement in all aspects of health service. If that is the case, which strategy may work better to scale up the admission capacity of the medical schools without compromising the quality of training and clinical service?

\section{2) Identifying the potential training sites}

With the existing medical schools teaching hospitals' capacity, it is unlikely to produce the desired number of specialists in the coming ten to fifteen years. Therefore, as the undergraduate program is already established outside university hospitals, the training sites for the scale up program can be mainly public hospitals which are going to have affiliation with the nearby medical schools. Specifically, general and referral public hospitals may be identified as the main training sites.

\section{3) Employing as many expatriates as possible for already and to be university affiliated hospitals}

Employing expatriate medical doctors has been practiced for several decades. But this time, it should be done very aggressively to bring a radical change in the number of specialists as it is going to be seen in the number of general practitioners. Definitely, this will incur costs to the government for about 5-6 years. Thereafter, the large number of graduates (specialists) will replace the expatriates. Probably, it is good to explore whether the economic crisis is also affecting the senior health professionals in developed countries. 
In some developed countries, the unemployment rate is continuously increasing. That may be a good opportunity for us to employee senior health professionals with affordable wedge.

\section{4) Establishing an incentivized collaborative consortium with medical schools outside Ethiopia}

This can be North-South or South-South collaboration. The South-South collaboration can be with medical schools in Africa, South America (English speaking) or India. Once a formal linkage has been established with as many medical schools as possible, potential instructors can come regularly on rotational basis (every 3-6 months). The instructors will not only be involved in teaching/coaching residents. They will also be engaged in providing clinical service, which is going to be an opportunity for our patients to benefit from their expertise. This kind of linkage is also an opportunity for instructors, who are going to come from outside medical schools:

- The government of Ethiopia or its partners will pay them a modest amount of money;

- They can bring their residents to have an experience in a third world country;

- This is a very important link for their academic career, knowledge and skill transfer;

- Therefore, this modality is probably one of the best that needs to be explored in depth for its feasibility and affordability.

\section{5) Collaborating with private and charity based hospitals}

Although their number is few and their capacity is limited, establishing public-private partnership for the planned academic program can be initiated in small scale. This kind of partnership is an advantage for both parties: utilizing the majority of specialists in the country as instructors (the government's advantage) and improving academic career for the senior professionals working outside university hospitals (private partners' advantage).

6) Scaling up the in-service training on basic and comprehensive emergency obstetric and newborn care (BEmONC, CEmONC)
A health facility is labeled as "EmONC facility" when it is providing either BEmONC or CEmONC service. According to the UN standards, there are 9 signal functions for EmONC (administering parenteral antibiotics; parenteral uterotonics; parenteral anticonvulsants; removal of retained products of conceptus; manual removal of placenta; instrument assisted vaginal delivery; and neonatal resuscitation for BEmONC; plus performing abdominal obstetric surgery and blood transfusion for CEmOC) (12). A nationwide health facilities survey in 2011 identified that the quality and availability of EmONC indicators in Ethiopia were much below the recommended levels, which might be a contributing factor for the maternal and perinatal mortality to be among the highest in the world (13)

The authors of this article had a chance to visit more than 200 health facilities across the nation and the observation was consistent with the finding of the national survey. Furthermore, as a $\mathrm{BEmONC}$ and CEmONC trainer for more than 10 years, the authors observed that the trainees (particularly the midlevel health professionals) had very rudimentary knowledge and skill. With nearly three weeks' theoretical and practical training, however, the majorities were catching up, and we checked their performance back in their work place. After conducting several trainings and supportive supervisions (on-site refresher training using patients and mobile skill lab), we concluded that BEmONC and CEmONC in-service trainings are a real remedial courses pertaining to obstetric and perinatal health for the midlevel health professionals. The FIGO Save the Mothers Initiative on EmOC training around Ambo/Ethiopia has also demonstrated a reduction in the case-fatality rate of obstetric complications (14). Other countries have also shown significant improvements in maternal and perinatal health by scaling up BEmONC and CEmONC in-service trainings $(15,16)$.

Despite its big advantage in upgrading the knowledge and skill of maternal and neonatal health care providers, very few NGOs and other partners are sporadically engaged in supporting this program in Ethiopia. As a result, the big regional states (Oromia, Amhara and Southern Nations Nationalities and Peoples) with more than $80 \%$ of the country's population had $0.4-0.5$ EmOC facilities per 500, 000 people although the 
minimum recommendation is 5 EmOC facilities (13).

The advantage of scaling up this type of inservice training is that it is an opportunity to timely pick those graduates with poor knowledge and low skill. Particularly, nowadays, as the authors of this article observed on-site and from the referred patients, probably because of the huge number of students and continually flourishing private health science colleges, on job clinical performance of the graduates is below the standard. Therefore, urgently planning and implementing a large scale BEmONC training across the nation is probably one of the top priorities to upgrade the midlevel health professionals' theoretical knowledge and skill, and in the long run, to reduce the maternal and perinatal mortality in Ethiopia.

\section{7) Availing the most preferred contraceptive methods-injectables, implants, transdermal patch and quinacrine sterilization}

As the majority of the youths are educated and aware of the advantages and disadvantages of different types of contraceptive methods, their demand is likely to increase and may continue requesting for the most preferred ones. As the 2011 EDHS has shown, among available contraceptive methods in the public health facilities, the use of injectable contraceptive methods has increased by 7 -fold (from 3\% in 2000 to $21 \%$ in 2011). Similarly, the demand for implant contraceptive methods has been increasing during the same period, but there was no change in the percentage of pills, condoms and intrauterine device (IUD) use. This is in contrast with the worldwide contraceptive use prevalence report; the top five contraceptive methods used are female sterilization (223 million), IUDs (169 million), pills (104 million), condoms (90 million) and injectables (41 million) (17).

This finding indicates that, although pills and condoms are widely available in Ethiopian health facilities, the majority of the clients' preference is the injectables and implants. This is also true in our day- to-day observation. One of the authors (YB) had a chance to visit several health centers and hospitals since 1998. The health providers usually express their challenge with the deficiency of injectable and implant contraceptive methods. This happened because of the high demand of clients for injectable contraceptive methods. The chronic shortage of injectable contraceptive methods is very common in rural health facilities, where the majority of the users are farmers and women probably with low socioeconomic status. This is happening despite the fact that the majority of the reproductive health related problems (high fertility rate, short birth interval, high home delivery, several cases of obstructed labor and uterine rupture, high maternal and perinatal mortality and harmful traditional practices) are very common among rural women $(10,18,19)$.

Availing the preferred contraceptive method is a very crucial step for the success of the family planning program in particular and for the overall maternal and perinatal health in general. Some years ago, a study reported that $91 \%$ of the women continued using the contraceptive method among those who received their preferred method, and $72 \%$ discontinued among those who did not receive their preferred method (20). The implication is that the high unmet need for contraception might have also contributed to the high maternal and perinatal mortality. According to the Guttmacher Institute's report, doubling the global investment in family planning services would reduce maternal deaths by two-thirds and infant deaths by half (21).

The unfortunate story is that while injectable and implants are repeatedly out of stock, it is not uncommon to discard expired pills because of low demand and high supply. Therefore, availing the preferred contraceptive method in all health facilities is expected to increase the injectable contraceptive use prevalence, and may reduce the initiated contraceptive method discontinuation. The authors' opinion is that preventing unwanted pregnancy, limiting the number of children and adequate childbirth spacing will have an impact on the reduction in maternal and perinatal mortality.

The previous surveys and observations were based on the assessments done on the available and distributed contraceptive methods in Ethiopia (combined oral contraceptive pill, progesteroneonly pill, Depo-Provera injection, implants, copper coated IUD, condoms, female and male surgical sterilization). However, other contraceptive methods widely used in other parts of the world (contraceptive patch, intrauterine system, vaginal ring, quinacrine non-surgical female sterilization) are not yet imported for public use. The 
intrauterine system (IUS) is a progesterone releasing intrauterine device, which is a modification of copper-T IUD and may not change the clients' compliance with IUD.

However, the contraceptive patch or transdermal patch (currently available in the form of Ortho Evra) is probably the best alternative with $99 \%$ efficacy that the majority of our women are expected to prefer it. Because of its simplicity in use and relatively long duration of action, compliance is better than oral contraceptive pills $(22,23)$. This contraceptive patch (about $5 \times 5 \mathrm{~cm}$ sticky patch) is applied to the skin on a weekly base and releases synthetic 20 microgram estrogen and 150 microgram progesterone per day (24). Despite adequate supply, one of the reasons for low utilization of contraceptive pills in Ethiopia is probably due the gastrointestinal side effects and forgetfulness. Several women fast long for religious reason and may not take anything per os for about 18-24 hours, which is likely to increase the adverse effects and failure to take the pills.

On the other hand, the quinacrine nonsurgical sterilization may be the future hope for the majority of the women. Unlike the worldwide report (17), sterilization is not adequately practiced in Ethiopia probably because of fear of the surgery, unavailability of the service, lack of awareness, religious or cultural factors. Because of the non-invasive nature of the procedure, and application not requiring a highly skilled person, quinacrine sterilization is probably the best option for developing countries including Ethiopia.

Quinacrine hydrochloride was developed in the late 1920's, primarily as antimalarial drug, which was also used to treat giardiasis, systemic lupus erythematousis, and rheumatoid arthritis. It was also used in sclerosing the pleural cavity. Quinacrine was used for female sterilization in the 1970s for the first time in Chile (25). Quinacrine pellets are inserted through the vagina into the uterine cavity by a device similar to that used to insert IUD. Insertion does not need a highly skilled person. The inserted pellets dissolve in the uterine cavity and results in inflammatory reaction leading to fibrosis and occlusion of the cornual area (fallopian tube ostium) and the intramural portion of fallopian tubes. Like any interventions, there are some mild side effects but not as high as the surgical sterilization. So far, more than 100 ,
000 women were sterilized with quinacrine pellets worldwide (26).

American food and drug authority (FDA) phase III clinical trial on quinacrine sterilization is not yet released. However, quinacrine sterilization was in practice in several South America and South Asian countries without FDA approval. According to the Wikipedia (the free encyclopedia), this method is currently legally used "off-label" in the United States, until final FDA approval of the method is obtained (27). The sole distributors in America and other parts of the world are the Center for Research on Population and Security and the International Federation for Family Health.

Some say that quinacrine is the most revolutionary birth control which has the potential for curbing rampant population growth in developing countries and can save the lives of millions of women who would otherwise die as a result of unwanted childbearing $(28,29)$. There are also other data that support its high efficacy and better compliance of women (30). Furthermore, there are several drugs which are used in large scale without FDA approval (misoprostol for prevention and treatment of postpartum hemorrhage, early pregnancy termination, and cervical ripening or labor induction; artemisinin derivatives for treatment of malaria). Therefore, the issue of FDA approval should not be a limitation to use quinacrine sterilization as an option for permanent female contraceptive methods. Particularly, in the rural areas of Ethiopia where the total fertility rate is high and highly skilled health professionals are very scarce, the benefit of quinacrine sterilization is indispensable.

In short, availing the preferred contraceptive methods (particularly injectable, transdermal patch and quinacrine sterilization) is an important intervention to increase the temporary and permanent contraceptive use prevalence rate and reduce maternal and perinatal mortality related to unplanned pregnancies and high fertility.

\section{8) Including iron infusion in the essential drugs and supplies list}

It was noted that obstetric hemorrhage is one of the leading causes of maternal mortality in Ethiopia and in other Sub Saharan African countries (31). It was also identified that the blood 
transfusion setting (because of lack of blood banks and peoples' resistance to donate blood) in public health facilities is incapacitated $(32,33)$. Blood loss is the common cause of iron deficiency anemia. Transfusing human blood when the condition of a patient due to blood loss is lifethreatening may be an unavoidable life-saving intervention. However, there are borderline clinical conditions (usually due to a moderate blood loss or other causes) which can be managed with other modalities like Iron infusion.

Iron infusion is practiced in few private hospitals in Addis Ababa. In public hospitals outside Addis, the available options for treatment of severe anemia are whole blood transfusion (which is always scarce) or iron tablets. The possibility of blood transfusion becomes very difficult as we go far from the center. Therefore, patients in remote areas are likely to benefit most from iron infusion.

Establishing blood banks in all zones and creating public awareness about the safety of donating blood are the top priorities in the treatment of severe blood loss anemia. In parallel, importing or producing iron infusions for moderate anemia needs to be included in the essential drugs and the supply list. Thereafter, iron infusion guidelines can be developed. Since iron deficiency anemia due to other causes is highly prevalent in Ethiopia, availing iron infusion in the market will not only benefit mothers with blood loss but also other patients with iron deficiency anemia.

Although iron has been used to treat anemia for more than 300 years, standardized formulation (oral iron) was not possible until the $19^{\text {th }}$ century. Oral iron, however, still has several problems: gastrointestinal toxicity occurs in 35\%-59\% of patients, a long course of therapy is needed (up to 3 months), poor adherence and poor gastrointestinal absorption are common. Although iron infusion is not without risk, the incidence of infusion reaction is rare (34). Parenteral iron administration was in practice starting from the 20 th century. One extensive review concluded that "given the demonstrated safety and efficacy of intravenous iron in a broad spectrum of diseases associated with iron deficiency anemia, the current paradigm that oral iron is first-line therapy should be reconsidered". The preferred type of products are: low molecular weight iron dextran, ferric gluconate, iron sucrose, ferric carboxymaltose, ferumoxytol (approved by FDA), and iron isomaltoside $(35,36)$.

\section{9) Scaling up the women's group approach}

In this review, one of the major problems identified as a risk factor for high maternal and perinatal mortality was extremely low skilled person attended delivery. However, it should be noted that skilled person attended delivery might not necessarily mean health facility delivery. In the developed world, there was no maternal death in four studies including 39,478 planned home and planned hospital births. A meta-analysis including a total of 342,056 planned home and 207,551 planned hospital deliveries has shown that the PMRs were the same; however, planned home births were associated with significantly elevated neonatal mortality rates (37).

In the last three decades, several countries in the world achieved a significant reduction in maternal and neonatal mortality by implementing a community based participatory intervention (3842). In Ethiopia as well, the new health 'cadre' for the community (the health extension workers) are deployed starting from 2005. However, guiding the community to be part of the solution (specifically letting the women participate in problem identification, priority setting, designing strategies, implementing the feasible ones) was not as vibrant as it is now, where the weekly activity and vital statistics regarding maternal and newborn health are coming to the regional health bureau level through the established networking (women health development team - health post health center - woreda health office - zonal health department - regional health bureau). The health extension worker reports the data every Tuesday to the 'Command Post' established at the zonal health department.

The nucleus for the community based health promotion and intervention is the Women Health Development Team (WHDT) (previously called The Health Development Army), which is under the umbrella of Women Development Team. The Women Development Team is organized to address health, education, agriculture, social and other issues. Each WHDT is composed of 5-6 women members (one of the members is a leader, trainer, and a reporter). 
The health extension worker in that community, in addition to the supervisory role, discusses women's health related matters with the leaders and occasionally with the community. This initiative creates a forum to discuss the women's health issues at the community (chaired by the leader), health center, woreda health office, zonal health department and regional health bureau level. Those women who implemented the whole health extension package are recognized as a team leader and their family is labeled as Model Household.

In the old times, community-based health interventions used to be prescribed by policy makers without involving the community in decision-making. If there is a possibility to consult the community members, usually it did not involve the women. These days, however, there are ample evidences how much working with the community has positively changed the maternal and neonatal health in the developing countries, specifically in South Asia. A strategy that involves the community to promote universal access of women to antenatal care, skilled health personnel attended birth and early postpartum care has been shown to significantly reduce maternal and neonatal mortality (37-41) (Table 1).

Table 1: Summary of community based interventions and maternal and neonatal health

\begin{tabular}{|c|c|c|c|c|}
\hline Author & study design & Location & Intervention & Major outcomes/ conclusions \\
\hline $\begin{array}{l}\text { Rahman A et } \\
\text { al } 2011\end{array}$ & $\begin{array}{l}\text { Prospective } \\
\text { cohort }\end{array}$ & Bangladesh & $\begin{array}{l}\text { Improving } \\
\text { established links } \\
\text { between } \\
\text { community- \& } \\
\text { facility-based } \\
\text { services }\end{array}$ & $\begin{array}{l}\text { Perinatal mortality reduced by } \\
36 \% \text {. ANC, facility delivery \& } \\
\text { C/S delivery rate significantly } \\
\text { increased }\end{array}$ \\
\hline $\begin{array}{l}\text { Kirkwood } \\
\text { BR et al } \\
2013\end{array}$ & $\begin{array}{l}\text { A cluster } \\
\text { randomized } \\
\text { trial }\end{array}$ & Ghana & $\begin{array}{l}\text { Volunteers made } \\
\text { home visits to } \\
\text { pregnant women } \\
\text { in } 98 \text { zones }\end{array}$ & $\begin{array}{l}\text { An increase coverage of home } \\
\text { visits on the day of birth lead to } \\
\text { the substantial reduction in } \\
\text { neonatal mortality rate }(12 \%)\end{array}$ \\
\hline $\begin{array}{l}\text { Siddhartha } \\
\text { Gogia S et al } \\
2010\end{array}$ & $\begin{array}{l}\text { Systematic } \\
\text { review by } \\
\text { including } 5 \\
\text { trials }\end{array}$ & South Asia & $\begin{array}{l}\text { Home visits } \\
\text { during all stages } \\
\text { of pregnancy and } \\
\text { home-based } \\
\text { treatment }\end{array}$ & $\begin{array}{l}\text { Home visits for antenatal and } \\
\text { neonatal care, together with } \\
\text { community mobilization } \\
\text { activities, are associated with } \\
\text { reduced neonatal mortality and } \\
\text { stillbirths }\end{array}$ \\
\hline $\begin{array}{l}\text { Prost A et al } \\
2013\end{array}$ & $\begin{array}{l}\text { Systematic } \\
\text { review and } \\
\text { meta-analysis }\end{array}$ & $\begin{array}{l}\text { Bangladesh, } \\
\text { India, Malawi, } \\
\text { and Nepal }\end{array}$ & Variable & $\begin{array}{l}\text { Women's groups practice led to } \\
\text { substantial reductions in } \\
\text { neonatal and maternal } \\
\text { mortalities }\end{array}$ \\
\hline $\begin{array}{l}\text { Tripathy P et } \\
\text { al } 2013\end{array}$ & $\begin{array}{l}\text { A cluster } \\
\text { randomized } \\
\text { controlled } \\
\text { trial }\end{array}$ & India & $\begin{array}{l}\text { Village women } \\
\text { participated in } \\
\text { four-phase cycle } \\
(\text { See Table } 4)\end{array}$ & $\begin{array}{l}\text { Women's groups reduced } \\
\text { neonatal mortality by } 45 \% \text { in } \\
\text { the } 2^{\text {nd }} \text { and } 3^{\text {rd }} \text { years, and } \\
\text { moderate maternal depression } \\
\text { by } 57 \%\end{array}$ \\
\hline
\end{tabular}

Furthermore, in resource-limited settings with poor access to health facility-based care, home visits for neonatal care by community health workers was found to reduce stillbirths, neonatal and infant deaths (43). As a result, home-based care can complement the facility-based care in those women with poor access to health facilities. The trials on home-based care were organized not only focusing on health promotion (early recognition of danger symptoms during pregnancy and after birth, promotion of delivery in a health facility or at home by a skilled birth attendant, 
exclusive breastfeeding, keeping the baby warm and clean umbilical cord care, identification of signs of neonatal illness and early reporting) but also on home-based interventions like skilled person attended delivery and treatment of neonatal problems including infections.

In general, the advantages of community based health promotion and interventions are to reach to the majority where a significant number of maternal and perinatal deaths occur, and potentially to bring behavioral changes in antenatal, intrapartal and newborn care practice (44-48). What is given a name in Ethiopia as Women Health Development Team is known in other countries as The Women's Group Approach. In both cases, the approach is almost the same (Table 2).

Table 2: Comparison of the women's group approach with the women's health development team

\begin{tabular}{|c|c|c|}
\hline Characteristics & The Women's group & $\begin{array}{l}\text { Women Health Development Team } \\
\text { (Ethiopia) }\end{array}$ \\
\hline Location & Community based & Community based \\
\hline Principle & $\begin{array}{l}\text { Participatory, community } \\
\text { mobilization }\end{array}$ & Participatory, community mobilization \\
\hline Target & Maternal and newborn health & Mainly maternal and newborn health \\
\hline $\begin{array}{l}\text { Community level } \\
\text { leaders/facilitators }\end{array}$ & $\begin{array}{l}\text { Local volunteer women } \\
\text { given brief training and who } \\
\text { can provide advice and } \\
\text { support for breastfeeding, } \\
\text { birth preparedness, newborn } \\
\text { care and immunisation. }\end{array}$ & $\begin{array}{l}\text { Local volunteer women with better } \\
\text { performance in the HEPs and who can } \\
\text { provide advice and support for } \\
\text { breastfeeding, birth preparedness, } \\
\text { newborn care and immunisation. }\end{array}$ \\
\hline Additional role of leaders & $\begin{array}{l}\text { House to house visits and } \\
\text { teaching pregnant women }\end{array}$ & $\begin{array}{l}\text { House to house visits and teaching } \\
\text { pregnant women }\end{array}$ \\
\hline Group members & $\begin{array}{l}\text { Not specified; just put as } \\
\text { group of women }\end{array}$ & 5-6 women form a team \\
\hline Action & $\begin{array}{l}\text { Groups of women work } \\
\text { together to identify and } \\
\text { prioritize key maternal and } \\
\text { neonatal health problems; } \\
\text { then develop local strategies } \\
\text { to implement, and evaluate } \\
\text { (Four-phase cycle) }\end{array}$ & $\begin{array}{l}\text { 5-6 women work together to identify and } \\
\text { prioritize key maternal and neonatal } \\
\text { health problems; then develop local } \\
\text { strategies to implement, and evaluate } \\
\text { (Four-phase cycle) }\end{array}$ \\
\hline Professional close support & Not defined & By health extension workers \\
\hline Meetings & Usually monthly & Usually weekly \\
\hline Linkage & Not defined & Well defined \\
\hline
\end{tabular}

Some of the conclusions drawn from a large crosssectional study in Ethiopia were: the integration of community based essential newborn care package within the health extension program (HEP) outreach activities was effective; the use of volunteer community health promoters was found as an effective strategy. However, the HEP outreach activities had little effect on skilled personnel attended delivery which was attributed to lack of technical staff, infrastructure, equipment, supplies and defective referral system (49).

In the authors' opinion, this gap will be corrected: 1) by establishing a functioning health facility linkage/referral system and women-health professional networking (See below); and 2) when adequate number of functioning health facilities and health professionals are in place as discussed above. In short, the Women Health Development Team, which is under implementation at the 
community level in Ethiopia, is evidence based. Thus, it has to be scaled up.

\section{0) Establishing women-health professionals networking}

In contemporary obstetrics, the consensus is that every pregnancy is a risk for the mother and her baby till proved otherwise. The majority of the pregnancy and birth related complications are unpredictable and late onset (unbooked emergencies). The good thing is that almost all pregnancy related complications to the mother are treatable before causing further damage. This is possible if appropriate actions (early identification, early intervention, and early referral) are taken on time. To take one or more of the appropriate actions, good knowledge and skill about pregnancy related complications are basic and rate limiting.

However, it is not uncommon for all of us in the field to be challenged with making appropriate decision on identification of obstetric complications or in outlining of management schemes, and requesting others' help. The degree of challenge does vary as the level of qualification in maternal health issues varies among different level of professionals. In clinical practice, whenever anyone is challenged with the case he/she encounters, it is a common practice to consult somebody either vertically or horizontally.

The challenge becomes more evident when there is no one around to be consulted or when the clinical condition of the patient is beyond the capacity of the health professionals. In such instances, health professionals may take one of the three actions: 1) continue observing the change with already taken action, 2) start trial of interventions empirically, 3) refer the patient to another health facility without communication (the most common scenario), and 4) very rarely, consult somebody working in a far-away health facility.

Because of such disorganized actions, it is very common to encounter patients who are unnecessarily delayed in another health facility. Such delays are usually due to wrong diagnosis. As a result, unnecessary interventions are performed; referred without performing any supportive and life-saving interventions, and referred to another health facility without ahead of communication. Secondly, because of lack of formal referral linkage (especially outside Addis), patients and relatives are usually told to go to any hospital and the referral paper is also tagged with "to any hospital". These are some examples to show how disorganized our referral system and inter-health facilities' linkages are.

Therefore, establishing a formal referral linkage is one important step. But, the more important is establishing a referral linkage with 24 hours inter-facilities open communication. This will give full freedom to health professionals to communicate to the next health facility, and facilities early intervention before further morbid complications occur to the mother and her baby.

Apart from establishing formal and functioning health facilities referral linkage, establishing professional networking is a new initiative and is expected to be more effective in helping challenged health professionals, and by large complicated pregnant women and their newborns. The big advantage of the planned professional networking is to let several pregnant women and their babies get access to the most senior health professionals in the field. This is actually establishing a kind of 'maternal health family'. The family members are women organized as a Women's Health Development Team, health extension workers, midwives, health officers, emergency surgical health officers, general practitioners, gynecologist and pediatrician. Except the gynecologist and pediatrician, the number of mothers and other professionals in the family can be large enough as deemed necessary.

The maternal health family members will be communicating each other on telephone to discuss maternal and newborn health issues (Figure 4), specifically regarding making clinical diagnosis and further intervention options. This is a kind of consultation via telephone (Tele medicine). Such networking is an advantage to avoid big delays at home and at health facilities. 


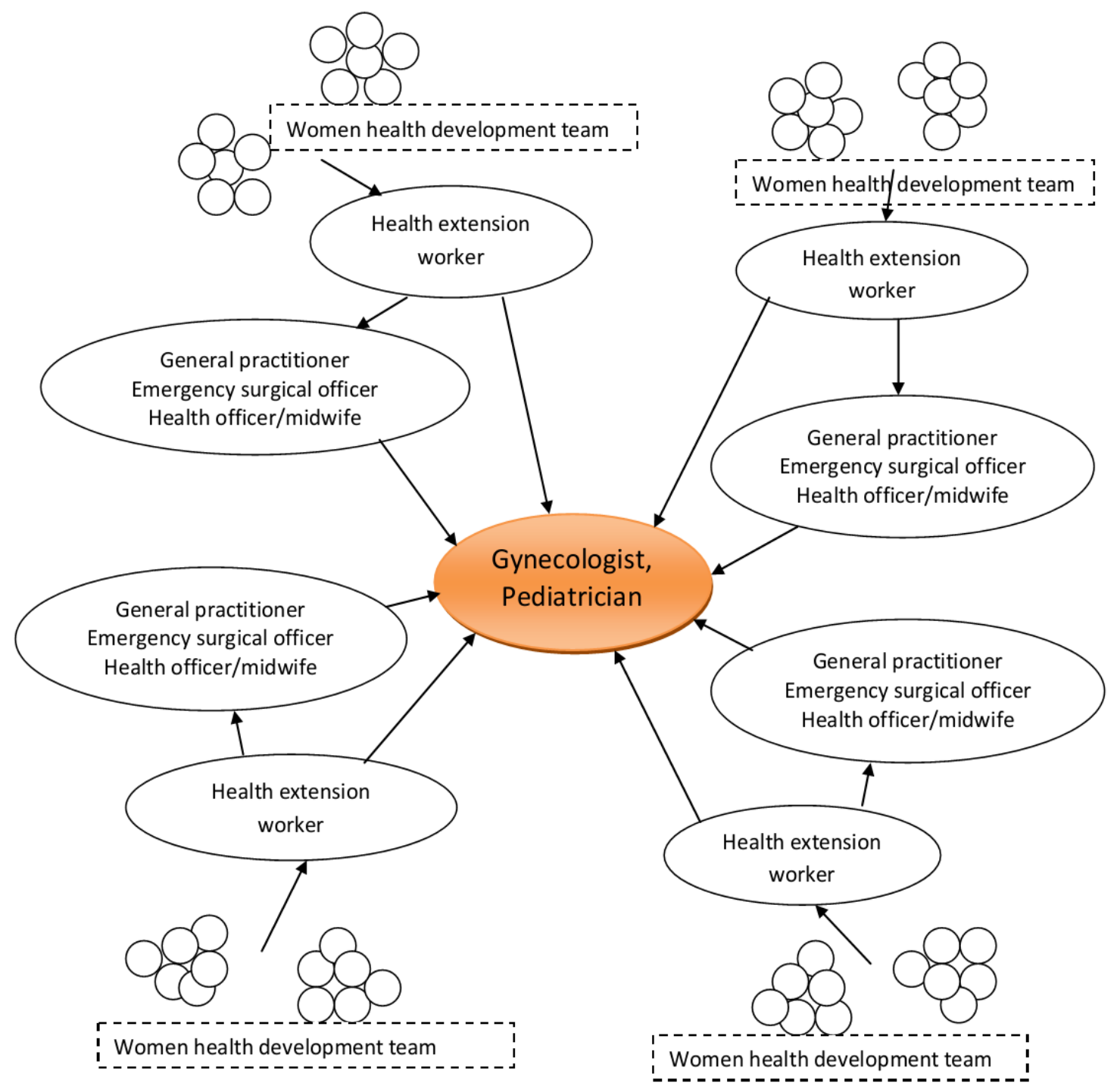

Figure 4: Women-health professionals networking model

The commonly observed phenomena specifically among the rural people are:

- Attempting to treat a sick pregnant woman with herbal therapy, holy water, religious or ritual activities;

- Keeping a laboring woman at home for 14 days and bringing her to a health facility after complications occurred if she is alive (usually due to obstructed labor, ruptured uterus, hemorrhagic shock, retained placenta, fistula); and

- Keeping a sick neonate at home (usually due to asphyxia, neonatal sepsis, pneumonia, meningitis, tetanus, jaundice, hypothermia, and hypoglycemia).
Therefore, with the to-be-established networking, the rural woman or her family members can have an opportunity to discuss the matter with the local leader or any of the health professionals in the maternal health family line and to timely take appropriate actions. Secondly, the maternal health family networking will also be an opportunity for health professionals working in health posts, health centers and primary/district hospitals to discuss maternal and neonatal health related issues with a gynecologist or pediatrician. Thirdly, the establishment of such a network will build the confidence of the women in the village and the health professionals in the line if there is any challenging problem; the presence of a senior 
professional with whom they can discuss the difficulties they encounter is encouraging for the women and their family to have early health care seeking behavior.

One of the authors (YB) has several experiences with telephone consultation among his previous students and trainees. It is a big relief for the consulting professionals and a very helpful decision for patients whose diagnosis is uncertain or the management plan is poorly defined. This kind of communication does not need much investment. Some compensation for the consulting health professionals may not cost much for the health facility where they are working provided that it is included in the financial management system.

The networking may be advantageous if it is in line with the inter-facility linkage or the referral system. The advantage of such linkage is that the consulted professional may have physical access to the referred patients, which is again an opportunity to give feedback to the referring health professionals in the established family (learning opportunity). Otherwise, in places where there is no gynecologist and pediatrician in and around the nearby locality, there should not be any boundary at least for consultation on telephone.

The authors are confident that gynecologists and pediatricians working in the public sector (university, the Ministry of Health owned hospitals), uniformed hospitals, private health facilities and NGOs will be happy to be the member of the maternal health family. Therefore, this is high time to establish this kind of network as an integral part of other activities to reduce maternal and neonatal mortality in Ethiopia.

\section{1) The Logic Model}

Finally, a logic model is developed to summarize the areas of intervention and expected outcomes (Figure 5). Government commitment and budget for maternal health and universal primary education are thought to be determining inputs for the envisaged outputs and outcomes. The authors are confident that the maternal mortality ratio will be reduced to 250 per 100,000 live births before 2025. 


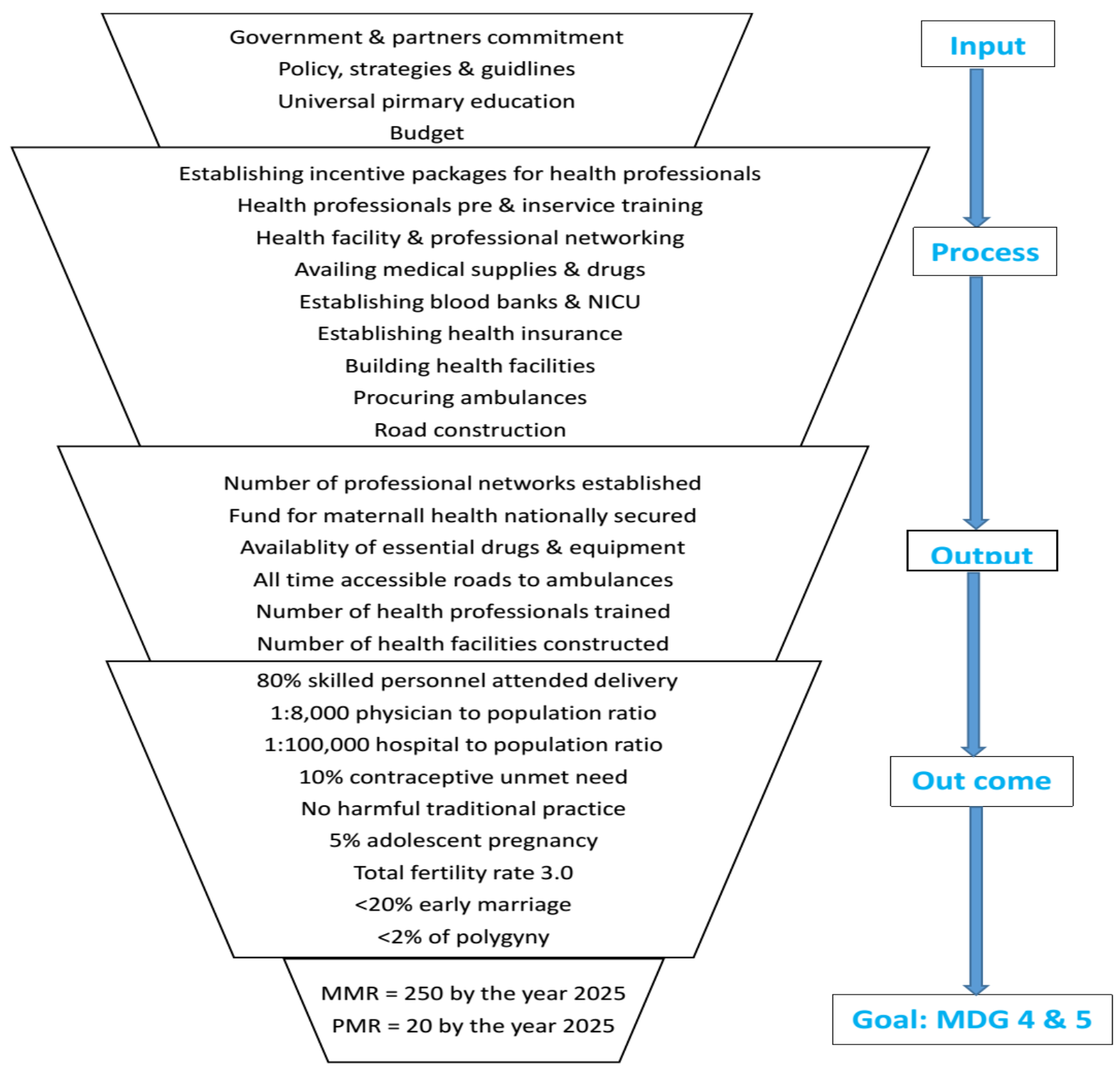

Figure 5: The logic model to show the areas of intervention and expected outcomes

\section{ACKNOWLEDGEMENT}

We would like to thank PANE and KMG Ethiopia for the modest financial granted for this review. We are also grateful to UNFPA Ethiopia for their generous financial support to cover the publication fee.

\section{REFERENCES}

1. Federal Democratic Republic of Ethiopia Ministry Of Health. Policy and practice, Information for action. Quarterly Health Bulletin 2009; 2(2):3-4.

2. Ethiopia Health Sector Development Programme 1997/98-2001/02. Report of the final evaluation of HSDP I. 2003 (V I). www.etharc.org/resources/download/finish/33/8 8

3. Federal Democratic Republic of Ethiopia Ministry Of Health. Health Sector Development Programme IV2010/11 - 2014/15. http -://pheethiopia.org/admin/uploads/attachment-721HSDPIV.pdf

4. Federal Democratic Republic of Ethiopia Ministry Of Health. National reproductive health strategy 2006-2015. March 2006.

5. Berhan Y. Medical doctors in Ethiopia: production, attrition and retention. Ethiop Med $J$ 2008; 46 (Supp 1): 1-75.

6. Berhan Y, Berhan A. Reasons for persistently high maternal and perinatal mortalities in 
Ethiopia: Part II - Socio-economic and cultural factors. Ethiop J Health Sci 2014. Special issue 1.

7. Kramer MS. The epidemiology of adverse pregnancy outcomes; an overview. J Nutr 2003; 133 (Suppl 2):1592-96.

8. Emmanuel T, Notion G, Gerald S, Addmore C, Mufuta T, Simukai Z. Determinants of perinatal mortality in Marondera district, Mashonaland East Province of Zimbabwe, 2009: a case control study. Pan Afric Med $J$ 2011; 8:7. http://www.panafrican-med-journal.com/

9. Okwaraji YB, Edmond KM. Proximity to health services and child survival in low- and middleincome countries: a systematic review and metaanalysis. BMJ Open 2012; 2: e001196.

10. Central Statistical Agency [Ethiopia] and ICF International. 2012. Ethiopia Demographic and Health Survey 2011. Addis Ababa, Ethiopia and Calverton, Maryland, USA: Central Statistical Agency and ICF International

11. Federal Democratic Republic of Ethiopia. Ministry of Health Health and Health Related Indicators 2010/2011). Policy planning directorate. www.moh.gov.et

12. Safe Motherhood: Providing Emergency Obstetric and Neonatal Care to All in Need. http://www.unfpa.org/public/home/mothers/pid/ 4385.

13. Admasu K, Haile-Mariam A, Bailey P. Indicators for availability, utilization, and quality of emergency obstetric care in Ethiopia, 2008. Int J Gynaecol Obstet 2011; 115(1):101-5.

14. Mekbib T, Kassaye E, Getachew A, Tadesse T, Debebe A. The FIGO Save the Mothers Initiative: the Ethiopia-Sweden collaboration. Int J Gynaecol Obstet 2003; 81(1):93-102.

15. Islam MT, Hossain MM, Islam MA, Haque YA. Improvement of coverage and utilization of EmOC services in southwestern Bangladesh. Int J Gynaecol Obstet 2005; 91(3):298-305;

16. Kongnyuy EJ, Hofman J, Mlava G, Mhango $\mathrm{C}$, van den Broek N. Availability, utilisation and quality of basic and comprehensive emergency obstetric care services in Malawi. Matern Child Health J 2009; 13(5):687-94.

17. Earth policy institute. World contraceptive prevalence by method. www.earthpolicy.org/images/uploads/graphs/

18. Central Statistical Agency [Ethiopia] and ICF International. 2006. Ethiopia Demographic and Health Survey 2005. Addis Ababa, Ethiopia and
Calverton, Maryland, USA: Central Statistical Agency and ICF International.

19. Bayou G, Berhan Y. Perinatal mortality and associated risk factors: a case control study. Ethiopian J Health Scie 2012; 22(3). 153-162.

20. Pariani S, Heer DM, van Arsdol MD Jr. Does choice make a difference to contraceptive use? Evidence from East Java. Stud Fam Plann 1991; 22(6):384-90.

21. Wind R. Advancing sexual and reproductive health worldwide through research, policy analysis and public education. 2009. http://www.guttmacher.org/media/

22. Audet MC, Moreau M, Koltun WD, et al. Evaluation of contraceptive efficacy and cycle control of a transdermal contraceptive patch vs an oral contraceptive: a randomized controlled trial. JAMA 2001; 285(18):2347-54.

23. Archer DF, Cullins V, Creasy GW, Fisher AC. The impact of improved compliance with a weekly contraceptive transdermal system (Ortho Evra) on contraceptive efficacy. Contraception 2004; 69(3):189-95.

24. Rivera R, Yacobson I, Grimes D. The mechanism of action of hormonal contraceptives and intrauterine contraceptive devices. Am J Obstet Gynecol 1999; 181 (5 Pt 1): 1263-9.

25. Zipper J, Medel M, Prager R. Alterations in Fertility Induced by Unilateral Instillation of Cytotoxic Compounds in Rats, Am J Obstet Gynecol 1992; 167:1203-1207.

26. Kessel E. Overview of First 100,000 Quinacrine Sterilization Procedures. 1997. available at http:// www.quinacrine.com/medicine/gynecology/

27. Wikipedia, The free encyclopedia. Mepacrine: http://en.wikipedia.org/wiki/Mepacrine.

28. Kessel E. Prospects for Nonsurgical Female Sterilization. INT. J. GYNAECOL. OBSTET. 1989. available at http:// www.quinacrine.com/archive/.

29. Medel M, Pasten L, Rivera M. Intrauterine Instillation of Chemical Cytotoxic Agents for Tubal Sterilization and Treatment of Functional Metrorrahagias. Int'l J Fertility 1969; 12: 28084.

30. Sarin AR, Sarin RK. Quinacrine sterilization (QS) among high-risk women: a study of 134 cases. Int J Gynecol Obstet 2003; 83(Suppl 2):S73-6.

31. Khan KS, Wojdyla D, Say L, Gülmezoglu AM, Van Look PFA. WHO analysis of causes of 
maternal death: a systematic review. Lancet 2006; 367: 1066-74.

32. Berhan Y, Berhan A. Reasons for persistently high maternal and perinatal mortalities in Ethiopia: Part I - Health system factors. Ethiop J Health Sci 2014; Special issue 1.

33. Bates I, Chapotera G, McKew S, van den Broek N. Maternal mortality in sub-Saharan Africa: the contribution of ineffective blood transfusion services. BJOG 2008; 115:1331-1339.

34. Auerbach M, Ballard H, Glaspy J. Clinical update: intravenous iron for anaemia. Lancet 2007; 369:1502-1504.

35. Heath CW, Strauss MB,

Castle WB. Quantitative aspects of iron deficiency in hypochromic anemia. $J$ Clin Invest 1932; 11:1293-1312.

36. Nissim JA. Intravenous administration of iron. Lancet 1947; 1:49-51.

37. Wax JR, Lucas FL, Lamont M, et al. Maternal and newborn outcomes in planned home birth vs planned hospital births: a meta-analysis. Am $J$ Obstet Gynecol 2010;203: 243.e1-8

38. Kirkwood BR, Manu A, Asbroek AHS, et al. Effect of the Newhints home-visits intervention on neonatal mortality rate and care practices in Ghana: a cluster randomised controlled trial. Lancet 2013; 381: 2184-92

39. Gogia S, Sachdev HS. Home visits by community health workers to prevent neonatal deaths in developing countries: a systematic review. Bull World Health Organ 2010; 88:658666B | doi:10.2471/BLT.09.069369.

40. Prost A, Colbourn T, Seward N, et al. Women's groups practicing participatory learning and action to improve maternal and newborn health in low-resource settings: a systematic review and meta-analysis. Lancet 2013; 381: 1736-46.

41. Tripathy P, Nair N, Barnett $S$, et al. Effect of a participatory intervention with women's groups on birth outcomes and maternal depression in Jharkhand and Orissa, India: a clusterrandomised controlled trial. The Lancet 2010; 375 (9721): $1182-1192$.

42. Lewycka S, Mwansambo C, Rosato M, et al. Effect of women's groups and volunteer peer counselling on rates of mortality, morbidity, and health behaviours in mothers and children in rural Malawi (MaiMwana): a factorial, clusterrandomised controlled trial. Lancet 2013; 381: 1721-35.

43. Rahman A, Moran A, Pervin J, et al. Effectiveness of an integrated approach to reduce perinatal mortality: recent experiences from Matlab, Bangladesh. BMC Public Health 2011; 11:914. http:www.biomedcentral.com

44. Bang AT, Bang RA, Baitule SB, Reddy MH, Deshmukh MD. Effect of home-based neonatal care and management of sepsis on neonatal mortality: field trial in rural India. Lancet 1999; 354: 1955-61.

45. Bang AT, Reddy HM, Deshmukh MD, Baitule SB, Bang RA. Neonatal and infant mortality in the ten years (1993 to 2003) of the Gadchiroli fi eld trial: effect of home-based neonatal care. $J$ Perinatol 2005; 25 (suppl 1): S92-107.

46. Kumar V, Mohanty S, Kumar A, et al. Effect of community-based behaviour change management on neonatal mortality in Shivgarh, Uttar Pradesh, India: a cluster-randomised controlled trial. Lancet 2008; 372: 1151-62.

47. Baqui AH, El-Arifeen S, Darmstadt GL, et al. Effect of community-based newborn-care intervention package implemented through two service-delivery strategies in Sylhet district, Bangladesh: a cluster-randomised controlled trial. Lancet 2008; 371: 1936-44.

48. Bhutta ZA, Memon ZA, Soofi S, Salat MS, Cousens S, Martines J. Implementing community-based perinatal care: results from a pilot study in rural Pakistan. Bull World Health Organ 2008; 86: 452-59.

49. Karim AM, Admassu K, Schellenberg J, et al. Effect of Ethiopia's Health Extension Program on Maternal and Newborn Health Care Practices in 101 Rural Districts: A Dose-Response Study. PLoS ONE 2013; 8(6): e65160. doi:10.1371/journal.pone.0065160. 